\title{
Relationship between Functional Fitness and Break Response in Elderly Drivers: Comparison with Young Driver
}

\author{
Ga Eun Kim', Ye Eun Choi', Su Seong Yang², Sun A Kim², Young Sook Bae' \\ 'Department of Physical Therapy, College of Health Science, Gachon University; ${ }^{2}$ Department of Biomedical Engineering, College of Health Science, \\ Gachon University, Incheon, Korea
}

Purpose: This study compared the functional fitness and brake response of elderly and young drivers to confirm the correlation between the functional fitness and brake response.

Methods: This study was a cross sectional observational design. Older drivers ( $>65 a g e, n=21$ ) and young adult drivers (20-40aged, $n=20$ ) were enrolled as subjects. The functional fitness of the subjects was measured using a senior fitness test consisting of a back scratch (BS), chair sit and reach (CSR), arm curl (AC), chair stand up (CSU), foot up and go (8-FUG), and 2-minute step (2-MS). The brake response used the virtual driving simulator to measure the brake reaction time (BRT) and braking distance (BD) according to the pedestrian protection and traffic signal compliance.

Results: The older drivers had a lower BS ( $p<0.000), \operatorname{CSU}(p=0.040)$, and 8-FUG $(p=0.011)$ than the young adult drivers. BS and 8-FUG showed a significant positive correlation with the BRT and BD of pedestrian protection and traffic signal compliance. CSU showed a significant negative correlation with the BRT of pedestrian protection and traffic signal compliance.

Conclusion: These findings suggest that the flexibility of the upper extremity, lower extremity strength, and agility are strongly correlated with the driving performance of elderly drivers.

Keywords: Break reaction, Drive, Elderly, Functional fitness

서 론

운전은 수단적 일상생활활동(instrumental activity of daily living)의 한 부분으로 분류하고 있으며, 노인의 일상생활뿐만 아니라 사회활동의 참여를 가능하게 함으로써 성공적 노화를 가능하게 하는 중요한 역 할을 한다. 운전은 노인뿐만 아니라 신경계 손상 환자들의 재활의 한 부분으로 여겨질 만큼 일상생활과 삶의 질에도 중요한 부분을 차지 한다. ${ }^{2}$

최근 통계청에 따르면 2017년 노인인구는 $13.8 \%$ 이며, 2060년에는 $41.0 \%$ 로 전망하고 있다. ${ }^{3}$ 이처럼 빠르게 증가되는 노인인구와 더불어 노인운전자는 2010 년 전체 운전자의 $21.1 \%, 2020$ 년에는 $33.8 \%$ 로 계속 증가될 것으로 전망하고 있다. 노인운전자들이 늘면서 교통사고 건 수 및 사상자 수도 급증하고 있으며, 고령층 운전자의 사고가 상대적 으로 위험한 것으로 분석되었다. 운전과 같은 복잡한 작업에는 감각 과 운동 및 인지기능이 필요하다. 그러므로 노인들에서 안전한 운전
을 위해서는 정상적인 시각, 인지능력 그리고 신체적 능력이 요구되 며, ${ }^{5}$ 노인운전자의 신체적 능력으로 운전 능력도 예측할 수 있다고 하 였다. ${ }^{6}$

노화와 관련된 운동의 변화(motor change)는 이동성과 운전능력에 영향을 미칠 수 있다. 연령이 증가하면 근력이 감소하면서 움직임의 속도도 감소된다. 이러한 신체적인 변화는 긴급한 상황에서 브레이 크 작동시간을 연장시키거나 휠 작동시간을 느려지게 할 수도 있다. ${ }^{8}$ 노인 운전자들이 젊은 운전자에 비하여 많은 지각시간과 반응시간 이 더 필요하다고 하며, 젊은 운전자보다 노인운전자에서 브레이크 반응시간이 더 느릴 수 있다. ${ }^{9}$ 브레이크 반응시간은 돌발상황에 대한 운전능력 중의 하나일 수 있다. 연령이 증가할수록 브레이크 반응시 간이 지연될 수 있으며 이로 인하여 운전의 안전성에 위험을 줄 수 있 는 요인이기도 하다. ${ }^{10}$ 또한 브레이크 반응시간의 측정이 노인의 운전 능력을 평가하기 위한 평가도구로 사용될 수 있다. ${ }^{9}$ 운전능력을 평가 함에 있어 실제 도로와 유사한 상황을 가상 현실로 제작한 운전시뮬 
레이터를 이용하며, 이는 운전능력의 연구, 훈련 그리고 평가에 광범 위하게 이용하거나 주로 사용한다.11,12 이전 연구에서는 운전 시뮬레 이터를 사용하여 노인과 젊은 운전자의 운전과제를 수행하는 동안 의 반응에 대하여 비교하였고, ${ }^{13}$ 최근에는 알츠하이머 질환이 있는 노인운전자의 운전행동을 연구하였다. ${ }^{14}$ 이처럼 운전 시뮬레이터는 실제 차량운전과 비교하여 운전능력과 운전 시 반응 시간을 측정하 는 평가도구로 사용되고 있다.

신체적 능력은 일상생활을 가능하게 하는 것으로 기능체력(functional fitness)이라고도 하며, 노인의 기능체력은 상지와 하지 근력, 지 구력, 유연성과 민첩성/균형으로 구성되어 있다. ${ }^{5}$ 노인운전자의 반사 적 동작의 빠르기를 나타내는 반응시간은 젊은 운전자에 비해 증가 되고, 이러한 능력의 저하와 반응시간의 증가로 인하여 운전 시 급박 한 상황에서 적절한 대처에 어려움이 있게 되며, 이는 사고로 유발시 키는 요인이 되기도 한다. 따라서 실제 운전상황에서 다른 자동차들 의 속도에 대한 착오나 실수로 인한 위험행동이 증가될 수 있다. ${ }^{16}$

이상 살펴본 바와 같이 운전능력은 인지기능과 기능체력에 의해 영 향을 받을 수 있으며, 노화로 인하여 저하된 기능체력이 운전 시 브레 이크 반응과 상관관계가 있을 것이라 생각된다. 이에 본 연구는 인지 기능이 정상인 노인 운전자와 젊은 운전자의 기능체력과 운전 시 운 전상황에 대한 브레이크 반응을 비교하고, 노인운전자에서 기능체력 과 브레이크 반응과의 상관관계를 확인하고자 하는 것이 목적이다.

\section{연구 방법}

\section{1. 연구대상 및 연구 절차}

본 연구의 대상자는 20-40대 성인 21명(평균 연령 35.3세), 65세 이상 노인 20명(평균 연령 71.4세)을 대상으로 하였다. 대상자는 포스터를 통하여 모집하였고, 연구참여를 원하는 자는 전화면담을 통하여 선 정기준과 제외기준에 맞는 대상자를 선정하였다. 대상자의 선정기준 은 다음과 같다: (1) 운전면허가 있는 자, (2) 최근 1년 이상 운전경험이 있는 자, (3) 우울증 같은 정신학적 질환이 없는 자, (3) 뇌경색, 뇌졸중 과 같은 신경학적 질환의 병력이 없는 자, (4) 독립적인 일상생활이 가 능한 자이다. 제외기준은: (1) 시력, 청력과 관련된 질환이 있는 자, (2) 정신상태검사(mini-mental state examination, MMSE) 점수가 27점 이 하인 자, (3) 연구절차를 수행하지 못한 자. 본 연구는 대상자의 표본 크기를 계산하기 위하여 G-power 3.1.7을 사용하였으며, power $=0.95$, $\alpha=0.05$, effect size $=0.5$ 로 계산하였다.

본 연구는 횡단면 관찰연구(cross-sectional observational study)이다. 대상자들은 일반적 특성(연령체중, 신장, 학력, 결혼상태), 운전 특성 (자가보고 형식으로 일주일에 운전시간, 본인의 운전 실력등), 건강상 태(음주와 흡연유무, 건강상태, 복용약물[복수응답] 등)는 설문지로
조사하였다. 그 후 MMSE, 기능적 체력 그리고 운전시뮬레이터를 이 용하여 운전 시 보행자 보호와 신호등 주시에 대한 브레이크 반응을 측정하였다. 대상자들은 데이터 수집에 대하여 동의하였고, 연구의 모든 절차는 가천대학교 윤리위원회에 승인 후수행되었다.

\section{2. 측정도구}

\section{1) 기능적 체력(function fitness, $\mathrm{FT}$ )}

기능적 체력은 노인의 FT를 측정하기 위한 평가방법인 노인체력 검사 (senior fitness test, SFT)를 사용하였다. ${ }^{15} \mathrm{SFT}$ 는 다음의 6 항목으로 구성 되어 있다: 등 뒤에서 손잡기(back scratch, BS), 의자에 앉아 발가락 닿 기(chair sit and reach, CSR), 팔굽 구부리기(arm curl, AC), 의자에서 일 어나기(chair stand up, $\mathrm{CSU}$ ), 8 걸음 걸어가기(foot up and go, 8-FUG), 그 리고 2분 제자리에서 걷기(2-minute step, 2-MS). BS는 상지의 유연성을 평가하는 것이며, 대상자의 한 손은 머리 뒤로 위치하게 하고, 다른 손 은 반대편 어깨뼈 하각(scapular inferior angle) 부위에 위치하게 한 후, 두 손의 가운데 손가락을 맞닿게 하였다. 왼손과 오른손의 구별 없이 대상자가 선호하는 쪽으로 수행하게 하였고, 등 뒤에서 손가락 사이 의 거리를 측정하였다. 양 손가락이 맞닿으면 “0”로 측정하였고, 측정 값이 클수록 상지 유연성이 저하된 상태이다. CSR은 하지 유연성을 평 가하는 것이며, 대상자는 의자의 가장 자리에 않게 한 후, 한쪽 다리는 굴곡시키고 다른 쪽 다리는 무릎을 펴게 하였고, 편 다리 측의 팔을 뻗 어 발가락을 잡게 하였다. 이때 의자에서 엉덩이가 떨어지지 않게 하 였으며, 손가락과 발가락의 거리를 측정하였고, 맞닿아 있으면 “0”로 측정하였다. 측정값이 클수록 하지 유연성이 저하된 상태이다. $\mathrm{AC}$ 는 상지 근력을 평가하기 위한 것이다. 대상자는 우세 손(dominant hand) 에 남자 $3.5 \mathrm{~kg}$, 여자 $2.5 \mathrm{~kg}$ 의 아령을 들고 30 초 동안 팔굽 관절의 완전 굽힘과 폄을 수행하게 하였고, 수행한 총 횟수를 측정하였다. 측정값 이 클수록 상지 근력이 좋은 상태를 의미한다. CSU은 하지 근력을 평 가하기 위한 것이다. 대상자의 양손을 가슴 위에 놓고 의자에 앉게 한 후, 의자에서 완전하게 일어선 후 다시 앉게 하였다. 30 초 동안 수행한 총 횟수를 측정하였고, 측정값이 클수록 하지 근력이 좋은 상태를 의 미한다. 8-FUG는 민첩성과 동적 균형을 평가하기 위한 것이다. 대상자 는 의자에서 일어나 앞으로 8 걸음을 걸어간 후, 돌아와서 의자에 다시 앉게 하였으며, 수행한 시간을 측정하였다. 마지막으로, 2-MS는 지구 력을 평가하기 위한 것이다. 대상자가 다리를 반대편 슬개골(patella)까 지 들어올리게 하면서 제자리에서 걷게 하였다. 2 분동안 완전하게 수 행한 횟수를 측정하였다. BS, CSU 그리고 8-FUG에 대한 test-retest 신 뢰도는 각각 $0.90,0.97$ 그리고 0.92 이었다. ${ }^{17}$

\section{2) 운전 상황에서의 운전자 반응 측정}

본 연구에서 사용된 가상 운전 시뮬레이터는 $2 \mathrm{D} / 3 \mathrm{D}$ 게임이나 상호작 
용 컨텐츠를 제작할 수 있는 개발 엔진인 Unity (5.6.0) 를 기반으로 C\# (Microsoft visual studio 2017)을 사용하여 제작되었다. 해당 가상 드라 이빙 시뮬레이터는 실험 참여자가 실제 운전을 하는 상황과 같은 반응 을 유도하기 위해 설계된 가상의 $3 \mathrm{D}$ 가상 도로에서의 시내 주행 환경 을 제공한다. 시야(visual field)는 차량에 탑승했을 때와 유사하도록 도 로에서 $1.09 \mathrm{~m}$ 위에서 실험참여자가 보는 것으로 구성되었고 이를 위 해 모니터는 40 inch $(927.6 \times 606.5 \times 227.6$ mm, UN40F5030AF, Samsung $)$ 로 해상도 $(1,920 \times 1,080$ Pixels)가 높은 모델을 사용하였다. 시뮬레이터 에서 실험 참여자는 $64 \times 105-110 \mathrm{~cm}$ 규격의 의자 위에서 시내 주행 시 나리오를 수행한다. 해당 의자는 대상자의 신체조건에 맞게 높이를 조 절한다. 피험자가 실제 시내 주행 상황과 최대한 유사하게 느끼도록 시 뮬레이터는 차량 주행 시 소음 자극을 제공하며, 이는 headset (SHS$100 \mathrm{~V}$ premium, Samsung)을 통해 실험 참여자에게 전달되었다.

본 연구는 보행자 보호, 교통신호 준수와 같이 운전 할 때의 상황에 대한 운전자의 반응을 브레이크 작동 반응으로 평가하기 위하여 총 2 개의 시나리오를 사용하였으며, 총 시나리오의 주행거리는 $9 \mathrm{~km}$ 로 구 성되어 있다. 액셀레이터와 브레이크가 포함된 Logitech G29 driving force 레이싱 휠 $(270 \mathrm{~mm}$ [weight] $\times 260 \mathrm{~mm}$ [height] $\times 278 \mathrm{~mm}$ [depth])과 pedal (167 mm [weight] $\times 428.5 \mathrm{~mm}$ [height] $\times 311 \mathrm{~mm}$ [depth])을 사용하 여 측정하였다. 실제 운전과 마찬가지로 액셀레이터를 밟을 경우 차량 은 주행하고, 브레이크를 밟을 경우 차량은 정지하도록 설정하였다. 속도는 한국의 시내도로 주행 규정에 맞춰 최고속도 $60 \mathrm{~km}$ 로 제한하 였다. 운전 시뮬레이터의 제동거리는 $17.8 \mathrm{~m}$ 로 설정하였다. 이는 한국 기준으로 도로표면이 마른 경우의 마찰계수 0.8 과 $9.8 \mathrm{mgh}$ 의 중력가 속도 및 주행속도 $60 \mathrm{~km} / \mathrm{h}$ 를 고려하여 계산되었다. ${ }^{18}$ 본 연구에 사용 된 시나리오는 2개로 구성하였으며 다음과 같다.

시나리오A (보행자 보호): 운전 중 갑작스럽게 보행자가 도로에 진 입하거나 공 과 같은 물체가 도로에 진입하는 상황에 대한 운전자의 반응을 3 회 측정하였다. 이 시나리오는 운전 중 예측할 수 없는 상황 에 대하여 운전자의 반응을 평가하였다. 대상자가 보행자나 물체를 확인한 후 브레이크 반응시간 $(\mathrm{ms})$ 과 제동거리 $(\mathrm{m})$ 를 측정하였으며, 3 회의 평균값을 사용하였다.

시나리오 B (신호등 주시): 주행 중 신호등이 초록색-> 빨간색으로 바뀌는 상황에 대하여 운전자의 반응을 3 회 측정하였다. 이 시나리 오는 운전 중 도로에서 진행과 정지 등과 같이 예측할 수 있는 상황 에 대하여 운전자의 반응을 측정하였다. 대상자가 신호등이 바뀌는 것을 확인 한 후 브레이크 반응시간 $(\mathrm{ms})$ 과 제동거리 $(\mathrm{m})$ 를 측정하였 으며, 3 회의 평균값을 사용하였다 (Figure 1).

\section{3. 자료분석}

모든 측정값들은 SPSS 23.0 버전(IBM Corp., Armonk, NY, USA)을 사
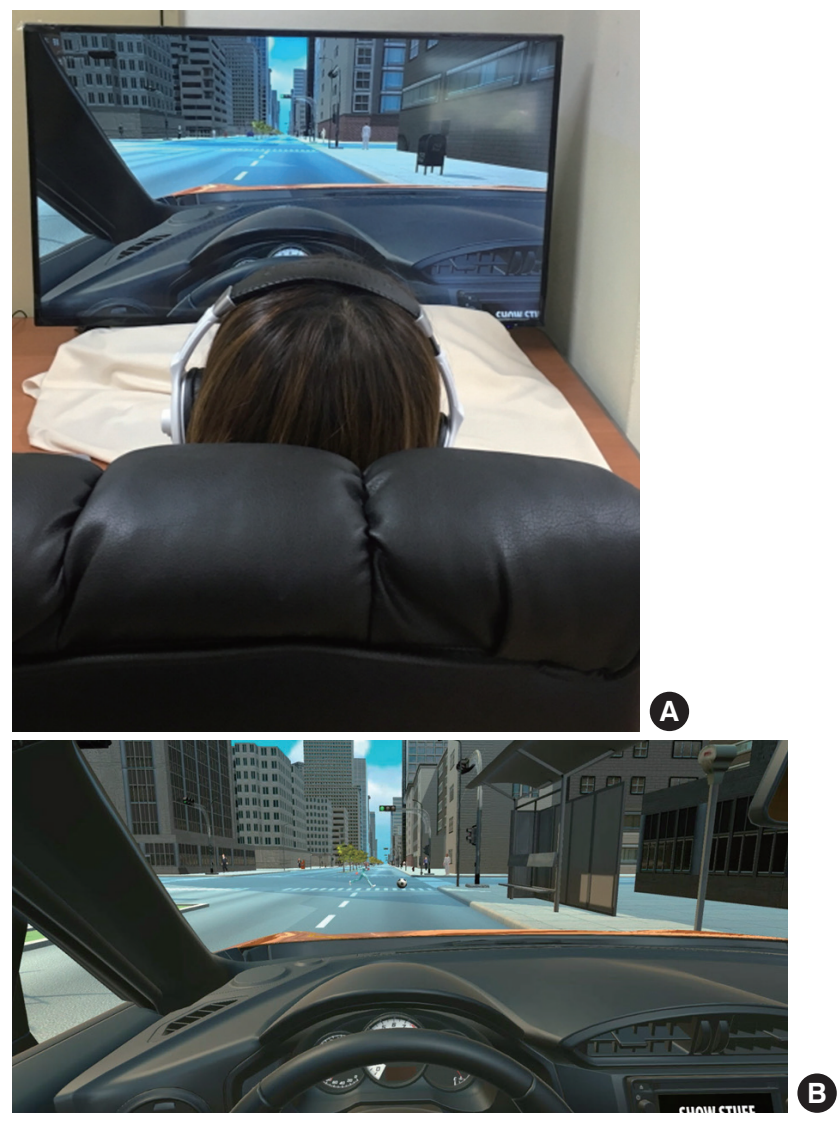

Figure 1. Experimental setup of the virtual reality driving simulator (A), and a screen of driving simulator (B).

용하였다. 대상자의 일반적인 특성은 기술통계로 확인하고, 정규성 분포는 Shapiro-Wilk test를 사용하였다. 대상자들의 성인그룹과 노인 그룹의 FT와 운전 시 브레이크 반응을 비교하기 위해서는 모수검정 인 독립 t-test (independent t-test)를 사용하였다. 각 그룹 내에서의 FT 와 운전 시 브레이크 반응과의 상관관계는 Pearson correlation 검사를 사용하여 분석하였다. 모든 변수는 평균 \pm 표준편차로 표시하였다. 본 연구의 유의수준은 0.05 로 설정하였다.

\section{결 과}

\section{1. 연구대상자의 특성}

대상자의 일반적인 특성, 운전 특성 및 건강상태는 Table 1에 나타내 었다.

\section{2. 젊은 운전자와 노인운전자의 FT와 운전 시 브레이크 반응 비교}

FT에서는 BS ( $\mathrm{p}<0.000), \mathrm{CSU}(\mathrm{p}=0.040), 8$-FUG ( $=0.011)$ 에서 노인운 전자가 젊은 운전자보다보다 기능이 감소되어 있었고, 그룹 간에 유 의한 차이가 있었다. 운전시 브레이크 반응은 보행자 보호에서 브레 
Table 1. Demographic characteristics, driving history and medical condition of the participants

\begin{tabular}{|c|c|c|}
\hline Variables (unit) & Older driver $(n=20)$ & Young driver $(n=21)$ \\
\hline \multicolumn{3}{|l|}{ Demographic characteristics } \\
\hline Age (year) & $71.40 \pm 6.48^{\mathrm{a}}$ & $30.22 \pm 7.45^{b}$ \\
\hline $\begin{array}{l}\text { Sex } \\
\text { Male } \\
\text { Female }\end{array}$ & $\begin{array}{c}15(75.0)^{\mathrm{b}} \\
5(25.0)\end{array}$ & $\begin{array}{r}12(57.2) \\
9(42.8)\end{array}$ \\
\hline Weight (cm) & $67.07 \pm 9.51$ & $65.75 \pm 0.30$ \\
\hline Height (kg) & $167.47 \pm 7.33$ & $168.72 \pm 9.27$ \\
\hline MMSE (score) & $29.15 \pm 1.75$ & $29.95 \pm 0.21$ \\
\hline \multicolumn{3}{|l|}{ Level of education } \\
\hline Elementary school & $2(3.8)$ & $0(0)$ \\
\hline Middle school & $3(19.2)$ & $0(0)$ \\
\hline $\begin{array}{l}\text { High school } \\
\text { University }\end{array}$ & $\begin{array}{r}11(42.4) \\
4(34.6)\end{array}$ & $\begin{array}{r}5(44.4) \\
16(55.6)\end{array}$ \\
\hline $\begin{array}{l}\text { Marital status } \\
\text { Married } \\
\text { Divorce } \\
\text { Bereavement } \\
\text { Single }\end{array}$ & $\begin{array}{l}13(65.0) \\
3(15.0) \\
3(15.0) \\
1(5.0)\end{array}$ & $\begin{array}{l}11(52.4) \\
1(4.8) \\
0(0) \\
9(42.8)\end{array}$ \\
\hline \multicolumn{3}{|l|}{ Driving history } \\
\hline $\begin{array}{l}\text { Driving times per week } \\
\leq 1 \\
2-3 \\
6-7\end{array}$ & $\begin{array}{r}7(30.8) \\
10(46.2) \\
3(23.1)\end{array}$ & $\begin{array}{r}2(11.1) \\
7(31.3) \\
12(55.6)\end{array}$ \\
\hline \multicolumn{3}{|l|}{ Hour driven per time } \\
\hline $\begin{array}{l}1 \text { year Accident } \\
\text { Yes } \\
\text { No }\end{array}$ & $\begin{array}{r}6(30.0) \\
14(70.0)\end{array}$ & $\begin{array}{r}3(14.2) \\
18(85.8)\end{array}$ \\
\hline $\begin{array}{l}\text { Self-reported driving skill } \\
\text { Newness } \\
\text { Good } \\
\text { Very good }\end{array}$ & $\begin{array}{c}3(7.6) \\
11(75.4) \\
6(26.9)\end{array}$ & $\begin{array}{c}2(9.5) \\
10(47.6) \\
9(42.9)\end{array}$ \\
\hline \multicolumn{3}{|l|}{ Medical condition } \\
\hline $\begin{array}{l}\text { Drinking } \\
\text { Yes } \\
\text { No }\end{array}$ & $\begin{array}{r}12(60.0) \\
8(40.0)\end{array}$ & $\begin{array}{r}16(76.1) \\
5(23.9)\end{array}$ \\
\hline $\begin{array}{l}\text { Smoking } \\
\text { Yes } \\
\text { No }\end{array}$ & $\begin{array}{r}7(33.3) \\
13(66.7)\end{array}$ & $\begin{array}{r}3(14.3) \\
18(85.7)\end{array}$ \\
\hline $\begin{array}{l}\text { Current health status } \\
\text { Very good } \\
\text { Good } \\
\text { Average } \\
\text { Bad }\end{array}$ & $\begin{array}{l}5(25.0) \\
3(15.0) \\
8(40.0) \\
4(20.0)\end{array}$ & $\begin{array}{l}3(14.2) \\
8(38.1) \\
9(42.9) \\
1(4.8)\end{array}$ \\
\hline $\begin{array}{l}\text { Taking medication } \\
\text { Hypertension } \\
\text { Diabetes } \\
\text { Musculoskeletal Disease } \\
\text { Digestive system disease } \\
\text { None }\end{array}$ & $\begin{array}{r}8(40.0) \\
6(30.0) \\
10(50.0) \\
6(30.0) \\
2(10.0)\end{array}$ & $\begin{aligned} 2 & (9.5) \\
1 & (4.8) \\
2 & (9.5) \\
3 & (14.2) \\
15 & (71.4)\end{aligned}$ \\
\hline
\end{tabular}

amean \pm standard deviation, ${ }^{b}$ number of person (\%).

이크 반응시간 $(\mathrm{p}=0.020)$ 와 브레이크 제동거리 $(\mathrm{p}=0.041)$ 에서 유의한 차이가 있었으며, 신호등 주시에서는 브레이크 제동거리 $(\mathrm{p}=0.048)$ 에 서 두 그룹간에 유의한차이가 있었다(Table 2).
Table 2. Comparison of functional fitness, break reaction between groups

\begin{tabular}{lccc}
\hline Variables (unit) & $\begin{array}{c}\text { Older } \\
\text { group }(n=20)\end{array}$ & $\begin{array}{c}\text { Young age } \\
\text { group }(n=21)\end{array}$ & p-value \\
\hline FT parameter & & & \\
Back scratch (cm) & $18.27 \pm 15.77$ & $1.99 \pm 2.28$ & $<0.000^{* *}$ \\
Chair sit and reach (cm) & $1.55 \pm 2.66$ & $0.00 \pm 0.00$ & 0.066 \\
Arm curl (number) & $27.50 \pm 7.34$ & $29.00 \pm 8.18$ & 0.489 \\
Chair stand up (number) & $19.80 \pm 6.13$ & $25.70 \pm 10.80$ & $0.040^{*}$ \\
8-foot up and go (sec) & $6.28 \pm 1.56$ & $5.18 \pm 0.94$ & $0.011^{*}$ \\
2-minute step (number) & $177.31 \pm 43.02$ & $184.69 \pm 32.23$ & 0.973 \\
Break reaction parameter & & & \\
Pedestrian protection & & & \\
Reaction time (msec) & $2.08 \pm 2.62$ & $0.85 \pm 0.43$ & $0.020^{*}$ \\
Braking distance $(\mathrm{m})$ & $23.14 \pm 35.56$ & $7.92 \pm 4.46$ & $0.041^{*}$ \\
Traffic light compliance & & & \\
Reaction time (msec) & $1.38 \pm 0.67$ & $1.21 \pm 0.39$ & 0.301 \\
Braking distance $(\mathrm{m})$ & $23.44 \pm 12.39$ & $17.13 \pm 2.58$ & $0.048^{*}$ \\
\hline${ }^{*} \mathrm{p}<0.05,{ }^{* *} \mathrm{p}<0.01$. & & &
\end{tabular}

Table 3. Pearson correlation coefficients between functional fitness, break reaction in older driver

\begin{tabular}{lcccccc}
\hline & \multicolumn{2}{c}{ Pedestrian protection } & & \multicolumn{2}{c}{ Traffic light compliance } \\
\cline { 2 - 3 } \cline { 5 - 6 } & $\begin{array}{c}\text { Reaction } \\
\text { time }\end{array}$ & $\begin{array}{c}\text { Braking } \\
\text { distance }\end{array}$ & & $\begin{array}{c}\text { Reaction } \\
\text { time }\end{array}$ & $\begin{array}{c}\text { Braking } \\
\text { distance }\end{array}$ \\
\hline Back scratch & $0.584^{*}$ & $0.550^{* *}$ & & 0.243 & 0.336 \\
8-FUG & & $0.760^{* *}$ & $0.557^{* *}$ & & $0.518^{*}$ & $0.519^{*}$ \\
Chair stand up & $-0.456^{* *}$ & -0.255 & & $-0.460^{*}$ & -0.447 \\
\hline
\end{tabular}

a8-foot up and go, ${ }^{*} p<0.05,{ }^{* *} p<0.01$.

\section{3. 노인운전자와 젊은 운전자에서 FT와 운전 시 브레이크 반응의 상관관계}

노인운전자의 $\mathrm{FT}$, 운전시 브레이크 반응의 상관관계를 확인한 결과, FT의 BS는 보행자 보호에서 브레이크 반응시간 $(\mathrm{r}=0.33, \mathrm{p}<0.05)$, 브 레이크 제동거리 $(\mathrm{r}=0.44, \mathrm{p}<0.01)$, 그리고 신호등 주시에서 브레이크 반응시간 $(r=0.47, \mathrm{p}<0.01)$, 브레이크 제동거리 $(\mathrm{r}=0.57, \mathrm{p}<0.01)$ 로 유의 한 양의 상관성이 있었다. 8-FUG는 보행자 보호에서 브레이크 반응 시간 $(\mathrm{r}=0.76, \mathrm{p}<0.01)$, 브레이크 제동거리 $(\mathrm{r}=0.55, \mathrm{p}<0.01)$, 그리고 신 호등 주시에서 브레이크 반응시간 $(\mathrm{r}=0.51, \mathrm{p}<0.01)$, 브레이크 제동거 리(r=0.51 p<0.01)로 유의한 양의 상관성이 있었다. 그리고 CSU는 보 행자 보호 $(r=-0.45, \mathrm{p}<0.05)$ 와 신호등 주시 $(\mathrm{r}=-0.45, \mathrm{p}<0.05)$ 의 브레이 크 반응시간 음의 상관관계가 있었다(Table 3). 그러나 젊은 운전자에 서는 FT와 브레이크 반응에서 상관관계가 나타나지 않았다.

\section{고 찰}

본 연구는 노인운전자와 젊은 운전자의 FT와 운전시 유발될 수 있는 
상황에 대한 브레이크 반응을 비교하였고, 또한 이들 변수 간의 상관 관계를 확인하였다. 본 연구결과, 젊은 운전자보다 노인운전자에서 $\mathrm{BS}, \mathrm{CSU}$ 그리고 8-FUG가 유의하게 저하되었고, 보행자 보호 시 브레 이크 반응 시간과 제동거리 그리고 신호등 주시에 대한 브레이크 제 동거리가 유의하게 증가되었다. 또한 노인운전자는 보행자 보호와 신 호등 주시의 브레이크 반응시간과 제동거리에서 $\mathrm{BS}, 8-\mathrm{FUG}$ 는 양의 상관관계가 있었으며, CSU는 음의 상관관계가 있었다.

BRT는 운전 시 물체를 본 후 브레이크 작동시키는 시간을 의미하 며, ${ }^{19}$ 이는 나이, 피로, 근육질환과 신경장애(neurologic disability)와 같 은 요인에 영향을 받을 수 있다. ${ }^{20}$ 또한 노인은 외부정보에 대해 브레이 크로 발을 옮기는 시간, 브레이크를 밟는 시간이 젊은 운전자보다 많 은 시간을 필요로 하여 위험한 상황에 대처할 수 있는 능력이 상대적 으로 저하된다고 하였다.21 본 연구결과, 보행자 또는 물체가 도로에 진 입하는 경우인 보행자 주시에서 젊은 운전자보다 노인 운전자에서 $\mathrm{BRT}$ 가 느렸고 $\mathrm{BD}$ 도 길었으며, 신호등 주시에서 $\mathrm{BD}$ 가 더 길었다. 그러 나 젊은 운전자에서도 신호등주시보다 보행자보호에서 BRT가 더 빨 랐다. 이는 젊은 운전자는 브레이크로 발을 옮기는 시간, 브레이크를 밟는 시간이 긴박한 상황에서는 더 빠르다는 의미이다. 이러한 결과 는 이전 연구와 유사한 것으로 운전 중 긴박한 상황에 대처할 수 있는 능력이 노인운전자에서 저하되어 있다고 저자는 예측하는 바이다.

BRT는 운전 평가에서 가장 많이 사용하는 평가 중 하나이며, ${ }^{22}$ 특 히 노인운전자에서는 느려진 브레이크 반응시간으로 인하여 운전 시 문제가 될 수도 있다. ${ }^{23}$ 본 연구에서 브레이크 반응시간은 자극을 인지하고 판단한 후 가속페달에서 감속페달로 발을 이동하여 감속 페달을 밟는 데까지 소요되는 시간이며, 제동거리는 감속페달을 밟 은 후 차량이 이동한 거리이다. 그러므로 브레이크반응시간은 하지 근육을 사용하여 가속페달에서 감속페달로 발을 이동하여 감속페 달을 밟는 데까지 소요되는 시간으로 해석할 수 있을 것이다. 본 연구 결과 젊은 운전자보다 노인운전자에서 근력과 순발력이 저하되어 있 었고, 신호등 주시보다 보행자 보호에서 브레이크 반응시간이 더 길 었다. 그러나 젊은 운전자는 신호등 주시보다 보행자 보호에서 브레 이크 반응시간이 더 짧았다. 이러한 결과는 노인운전자가 젊은 운전 자보다는 긴급한 상황에 대처하는 민첩성이 저하되어 있다는 것이라 예측할 수 있다. 또한 $\mathrm{CSU}$ 는 보행자 보호의 $\mathrm{BRT}, \mathrm{BD}$ 와 음의 상관관 계가 있었고, 8-FUG는 보행자 보호, 신호등 주시에서 $\mathrm{BRT}, \mathrm{BD}$ 와양의 상관관계가 있었다. 근력과 순발력은 매우 밀접한 양의 상관성이 있 으며, ${ }^{24}$ 노인에서는 근육의 단면적, 근력 그리고 순발력이 함께 감소된 다고 한다. ${ }^{2526}$ 그러므로 저자는 노인운전자가 운전 시 긴박한 상황에 서 대처하는 순발력과 근력의 저하는 느려진 $\mathrm{BRT}, \mathrm{BD}$ 와 상관성이 있 을 수다고 예측하는 바이다.

$\mathrm{FT}$ 중 BS는 상지 유연성을 평가하는 항목이다. 노인의 운전에 기여
하는 요인으로서 유연성의 중요성을 언급하였으며, ${ }^{27}$ 목의 유연성은 운전의 안전성과도 관련성이 있다고 하였다..$^{28}$ 이처럼 유연성은 노인 의 안전한 운전을 위해 중요한 요인이라고 할 수 있다. 그러나 본 연구 에서는 BRT를 측정하여 직접적인 상지 유연성과의 연관성을 입증하 기에는 부족한 부분이 있다. 그러므로 추후 연구에서는 이 부분에 대 한 근거를 제시할 수 있는 연구가 필요하리라 생각된다.

이상에서 살펴본 바와 같이 노인운전자에서 $\mathrm{BS}, \mathrm{CSU}$ 그리고 8-FUG는 안전한 운전 수행과 상관관계가 있을 것으로 예측되는 바 이다. 그러나 본 연구에서는 노인운전자의 운전경력에 대해서는 고려 하지 않았으며, 표본 수가 비교적 부족하여 연구결과를 일반화시키 기에는 어려운 점이 있다. 그러므로 추후 이러한 점을 보완한 연구가 필요할 것이라 생각된다

\section{ACKNOWLEDGEMENTS}

본 연구는 교육부의 대학특성화(CK) 사업 사업비를 받아 진행된 것 입니다(NRF-2014H1C9A2A02024284).

\section{참고문헌}

1. Golisz K. Occupational therapy interventions to improve driving performance in older adults: a systematic review. Am J Occup Ther. 2014; 68(6):662-9.

2. Lee BJ, Shin HK, Lee KS. The study of perception and necessity of driver rehabilitation in patients with CNS injury. J Korean Soc Phys. 2013; 25(5):352-9.

3. Korean Statistical information service. 2018. http://kosis.kr/index/index. do

4. Oh JS, Lee EY, Ryu JB et al. An analyses for main vulunerabel situations and human errors of elderly drivers' traffic accidents. J Transport Res. 2015;22(4):57-75.

5. Babaee S, Hermans E, Shen Y et al. Safety evaluation of older drivers based on psychological, physical and driving performance. Road Safety and Simulation International Conference. 2015.

6. Anstey KJ, Wood J, Lord S et al. Cognitive, sensory and physical factors enabling driving safety in older adults. Clin Psychol Rev. 2005;25(1):4565.

7. Stelmach GE, Nahom A. Cognitive-motor abilities of the elderly driver. Hum Factors. 1992;34(1):53-65.

8. Karthaus M, Falkenstein M. Functional changes and driving performance in older drivers: assessment and interventions. Geriatrics. 2016;1(2):12.

9. Shin HK, Lee HC. Characteristics of brake response time during the driving performance in the elderly. J Kor Phys Ther. 2009;21(3):81-6.

10. Meikle B, Devlin M, Pauley T. Driving pedal reaction times after right transtibial amputations. Arch Phys Med Rehabil. 2006;87(3):390-4.

11. Classen S, Brooks J. Driving simulators for occupational therapy screening, assessment, and intervention. Occup Ther Health Care. 2014;28(2): 
$154-62$.

12. Dickerson AE, Meuel DB, Ridenour CD et al. Assessment tools predicting fitness to drive in older adults: a systematic review. Am J Occup Ther. 2014;68(6):670-80.

13. Fraser DA, Hawken RE, Warnes AM. Effects of extra signals on drivers' distance keeping-a simulation study. IEEE Transactions on Vehicular Technology. 1994;43(4):1118-24.

14. Rizzo M, McGehee DV, Dawson JD et al. Simulated car crashes at intersections in drivers with alzheimer disease. Alzheimer Dis Assoc Disord. 2001;15(1):10-20.

15. Rikli RE, Jones CJ. Development and validation of a functional fitness test for community-residing older adults. J Aging Phys Act. 1999;7(2): $129-61$.

16. Lee SC, Oh JS, Park SJ et al. The relationship between driving confidence and driving behaviour in elderly and young drivers. Kor J Psychol. 2006; 12(1):81-102.

17. Milanović Z, Pantelić S, Trajković N et al. Age-related decrease in physical activity and functional fitness among elderly men and women. Clin Interv Aging. 2013;8:549-56.

18. Lim CS, Choi YW. The experimental study on the transient brake time of vehicles by road pavement and friction coefficient. KSCE. 2010;30: 587-97.

19. Zhang L, Baldwin K, Munoz B et al. Visual and cognitive predictors of performance on brake reaction test: Salisbury eye evaluation driving study. Ophthalmic Epidemiol. 2007;14(4):216-22.
20. Narhare P, Chaitra B, Maitri V. Comparative study of choice reaction time in young males and females. NJIRM. 2012;3(5):84-8.

21. Kim KB. The characteristics of traffic accidents and reduction methods by elderly drivers to prepare for the aging society-focused on Jeju. Jour. of KoCon.a. 2014;14(7):151-60.

22. Dickerson A, Reistetter T, Trujillo L. Using an iadl assessment to identify older adults who need a behind-the-wheel driving evaluation. J Appl Gerontol. 2010;29(4):494-506.

23. Marques CJ, Cabri J, Barreiros J et al. The effects of task complexity on brake response time before and after primary right total knee arthroplasty. Arch Phys Med Rehabil. 2008;89(5):851-5.

24. Kisner C, Colby LA, Borstad J. Therapeutic exercise: foundations and techniques. Philadelphia, FA Davis, 2017.

25. Frontera WR, Hughes VA, Fielding RA et al. Aging of skeletal muscle: a 12-yr longitudinal study. J Appl Physiol. 2000;88(4):1321-6.

26. Lexell J, Taylor CC, Sjöström M. What is the cause of the ageing atrophy? Total number, size and proportion of different fiber types studied in whole vastus lateralis muscle from 15-to 83-year-old men. J Neurol Sci. 1988;84(2-3):275-94.

27. Bickenbach JE, Chatterji S, Badley EM et al. Models of disablement, universalism and the international classification of impairments, disabilities and handicaps. Soc Sci Med. 1999;48(9):1173-87.

28. Lacherez P, Wood JM, Anstey KJ et al. Sensorimotor and postural control factors associated with driving safety in a community-dwelling older driver population. J Gerontol A Biol Sci Med Sci. 2013;69(2):240-4. 